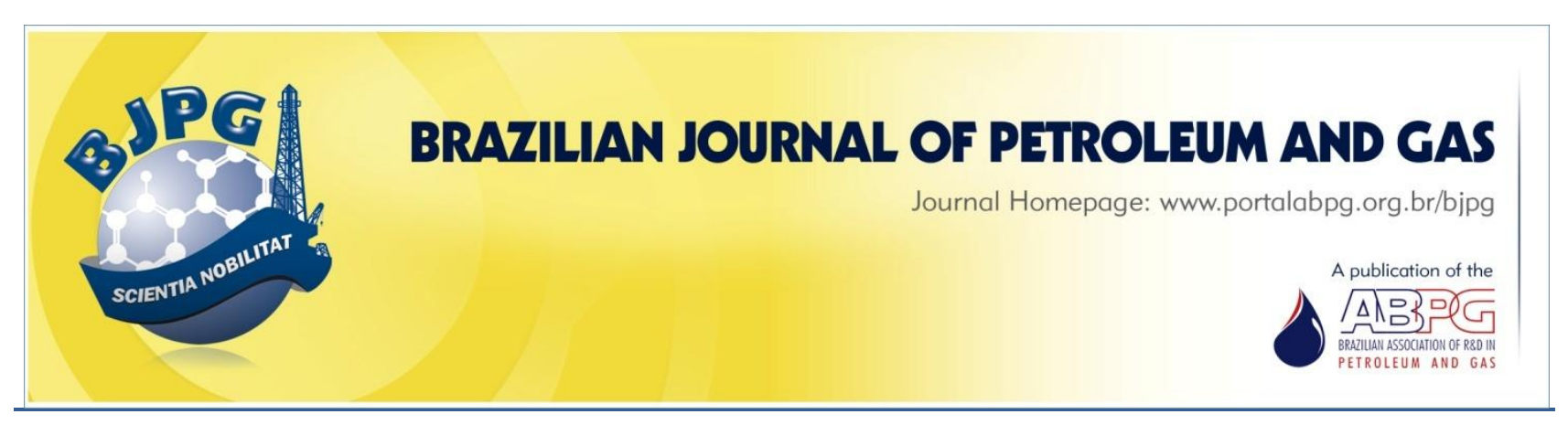

\title{
STUDY OF PRESSURE DROP IN A HORIZONTAL PIPE WITH A 90 JUNCTION FOR BIPHASIC LIQUID-GAS FLOW: MESH ASPECTS
}

\author{
${ }^{\text {a }}$ Ferreira, D. N. ${ }^{1}$; ${ }^{a}$ Marinho, J. L. G.; ${ }^{a}$ Oliveira, L. M. T. M. \\ a Universidade Federal de Alagoas, Unidade Acadêmica Centro de Tecnologia, UFAL, Maceió - AL, Brazil
}

Received: 07.11.2016 / Revised: 18.01.2017 / Accepted: 18.01.2017 / Published on line: 23.03.2017

\begin{abstract}
The occurrence of multiphasic flow is a constant in the oil sector. Transporting oil and gas is vital for this field, mainly because both oil and gas need to be moved before they can be used in the industry. In this context, pipelines stand out for representing safe and efficient means of transportation and for its low operating costs. Due to the economic importance of this activity, the study of pressure drop becomes relevant as a way of achieving greater efficiency in the transport. The use of computational fluid dynamics is a good alternative in this type of analysis as it can provide relatively fast and accurate results at a low cost. Since the results obtained by computational fluid dynamics have a significant connection with the numerical mesh used, the study of meshes becomes very relevant. This paper presents the study of pressure drop in a horizontal pipe with a $90^{\circ}$ junction for liquid-gas biphasic flow (oil/natural gas). Simulations were performed using Ansys-CFX $13.0^{\circledR}$ software to evaluate the influence of mesh type (structured and unstructured) and number of elements. The results were validated by Lockhart \& Martinelli correlation.
\end{abstract}

\section{KEYWORDS}

transport; two-phase flow; pressure drop; computational fluid dynamics; numerical mesh

\footnotetext{
${ }^{1}$ To whom all correspondence should be addressed.

Address: Unidade Acadêmica Centro de Tecnologia, UFAL, Av. Lourival Melo Mota, s/n Tabuleiro, Maceió - AL - Brazil ZIP Code: 57072-970 | Telephone: +55 82 3214-1271 |e-mail: davi.nf@hotmail.com doi:10.5419/bjpg2017-0003
} 


\section{INTRODUCTION}

The occurrence of a multiphase flow phenomenon, in which more than one phase is present, is a constant in many economically important sectors such as the oil industry (Marinho, 2008; Silva \& Marinho, 2014; Silva \& Marinho, 2016). In the oil industry, the presence of multiphase phenomena can be observed in different stages, from the flow in reservoirs to product columns, risers, processing plants and transportation pipelines.

When attempting increase operation efficiency, the study of pressure drop becomes an important factor. Salim et al. (2008) investigated the relation between pressure drop, flow rates, and materials used in pipelines for oil/water biphasic flow microchannel. Flow patterns and pressure drops were identified and, later, compared using LockhartMartinelli's models. They concluded that, for micro-chambers, there were similarities between gas-liquid and liquid-liquid flows, and there was a strong dependence on pressure drop variables, flow rate, and the materials used in the microchambers.

Carvalho (2013) examined experimentally the biphasic pressure gradient in large diameter ducts using the mixture model. For inclined ducts, deviations were obtained in the order about 3.2\% on the values of the quadratic mean deviations for the prediction of the pressure gradient, compared with several authors.

Although ducts have high installation costs, they are safe, efficient, and present low operation costs when compared to other forms of transportation. As the implementation cost of a flow system is relatively high, to minimize costs related to pipe transportation, more efficient hydraulic projects seek to increase flow capacity (Silva, 2008). According to Santos et al. (2010), due to the increased demand for transportation and production of heavy oils, the study of pressure drop in these situations becomes very important because it can alter the viscosity of the oils and it may cause a sharp pressure drop. Santos et al. (2010) examined the heavy oil transport by catenary using a free surface model in laminar flow rate for oil and turbulent flow rate for water. Results showed that the use of core-flow technique reduced pressure loss in 3.34 times compared with oil single-phase flow.

Factors of great importance that should be taken into consideration are the geographical obstacles. Due to space limitations, the use of junctions and connections becomes relevant to promote a differentiated behavior in relation to speed and pressure loss. Kim, Kojasoy, and Guo (2008) adapted Lockhart and Martinelli's (1949) correlation for calculating the two-phase pressure drop on connections. Marinho (2008) undertook a study to predict the behavior of two-phase flow (gas and oil) of Taylor bubble type in horizontal, vertical, and curved ducts. The study shows that pressure loss in the ducts decreases with an increase in pipe diameter and the amount of gas injected.

Computational fluid dynamics (CFD) is an important and widespread tool that enables the analysis of problems involving fluid flow. CFD involves a series of mathematical models that represent such problems and are applied in a given volume control with physicochemical characteristics similar to real ones (Oliveira et al. 2016). This tool is used commonly for phenomena that occur in the oil industry. Silva and Marinho (2014) studied the influence of the gas fraction in two-phase flow heavy oil/natural gas in a vertical pipe using Ansys CFX 13.0, comparing the results obtained with a single-phase model. They observed that, for gas volume fractions below 20\%, the single-phase flow represents well the characteristics of oil flow in presence of gas. Taleken et al. (2010) conducted studies in distillation columns, evaluating the influence of the electric heaters in hydrodynamic resistance. This study showed that the prediction of gas-liquid flow is fundamental to understand how the inter-phase transfer occurs. They also concluded that the presence of electrical resistance favors the homogenization of the phases, maximizing mass transfer. Oliveira et al. (2016) studied the behavior of fluids during a process of secondary recovery by water injection. They evaluated the oil recovery factor and the overall recovery efficiency. Souza (2009) analyzed the pressure gradient in the twophase flow water/air and concluded that the homogeneous model represents well the bubbled liquid-gas flow to obtain deviations of $6.16 \%$ and $0.37 \%$ compared to correlations of Lockhart and Martinelli and Friedel, respectively. 
Despite the constant development of commercial software, increasingly sophisticated, the representativeness of the analysis using CFD has a strong dependence on the correct insertion of boundary conditions and the numerical mesh used. For a better match of the numerical mesh to the geometry analyzed, it is made a discretization in this domain and the equations inherent to the problem are applied to every infinitesimal point of the volume analyzed. This numerical mesh can be of two types: structured and unstructured. Structured meshes are those in which elements are arranged in families of lines, making members (elements) of other families not to cross (Gonçalves, 2007). Unlike structured meshes, unstructured meshes are those in which the elements do not follow an array of lines families. Unstructured meshes are more versatile, adapt and suit more easily in discretization of irregular geometries (Maliska, 2004). Several authors studied the influence of the numerical meshes used in the results. Silva et al. (2015) analyzed the performance of various meshes to simulate a process of agitation in a mixing tank. They concluded that results were indifferent to the use of a layer of prismatic elements, despite the increased number of elements of the mesh, while the use of hexahedral cores reduced the number of elements and provided satisfactory results. Ferreira and Marinho (2015) studied the pressure drop for the two-phase flow (oil/natural gas) to a pipe with a $90^{\circ}$ junction using different types of meshes. They obtained a deviation of $3.44 \%$ and $1.24 \%$ for structured and unstructured meshes, respectively. Souza (2011) examined the mesh refinement in the simulation of a progressive cavity pump. He observed a strong influence of the size of the numerical mesh used in deviant behavior in relation to that experimentally found, and the need to reduce the discretization errors.

Therefore, this paper aims to study the pressure drop of the liquid-gas flow (oil and natural gas) in a horizontal pipe with a $90^{\circ}$ junction, where the simulations are intended to observe the influence of the type of mesh and the number of elements applied to calculate the pressure drop. ANSYS CFX $13.0^{\circ}$ commercial software was used in simulations and empirical correlations of Lockhart and Martinelli, and Kim, Kojasoy, and Guo were used to the validation.

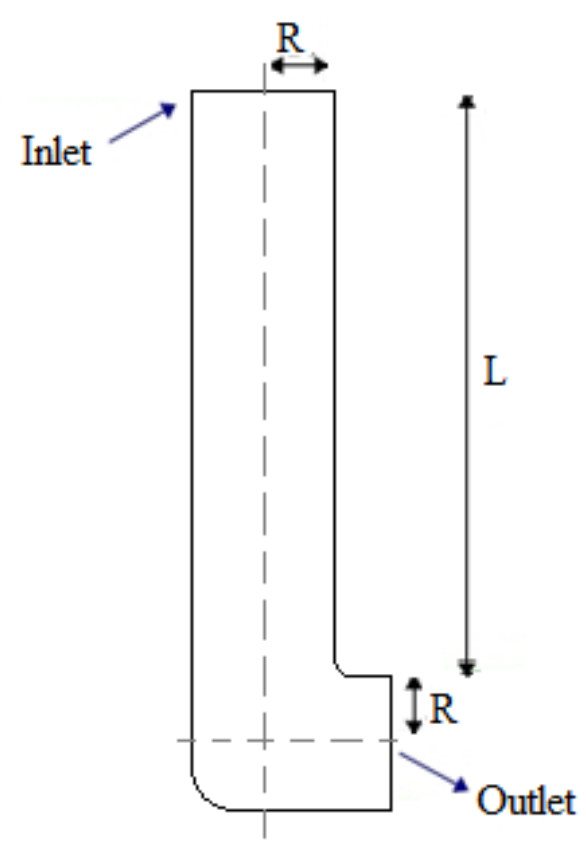

Figure 1. Representation of the top view of the horizontal pipe analyzed.

\section{METHODOLOGY}

\subsection{Geometry and mesh generation}

To solve the proposed problem, a horizontal pipe composed of a straight section $L=1 \mathrm{~m}$ long and a $90^{\circ}$ curve both with radius $R=0.025 \mathrm{~m}$ was considered, as can be observed in Figure 1.

Using the commercial software Ansys ICEM $\mathrm{CFD}^{\circledR}$, a geometry was generated based on the scheme represented in Figure 2. Other geometry composed only of a straight section was generated (Figure 3).

After the confection of the geometries, the meshes shown in Table 1were created.

Figure 4 shows the radial region of tetrahedral unstructured (1), hexahedral structured (2), and tetrahedral-prismatic unstructured (3) meshes.

The hexahedral structured and tetrahedral unstructured meshes were generated with a focus on the elements of the region close to the tube wall. This was done to obtain a better analysis of the distributed load loss caused by the roughness effects. The tetrahedral-prismatic unstructured meshes were generated with four layers of prismatic elements, also focusing on the pipe wall region. 


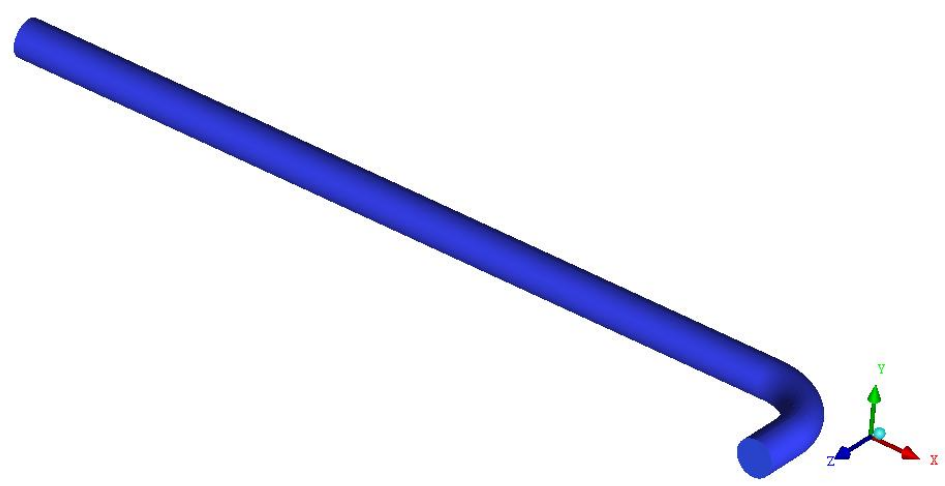

Figure 2. Geometry used.
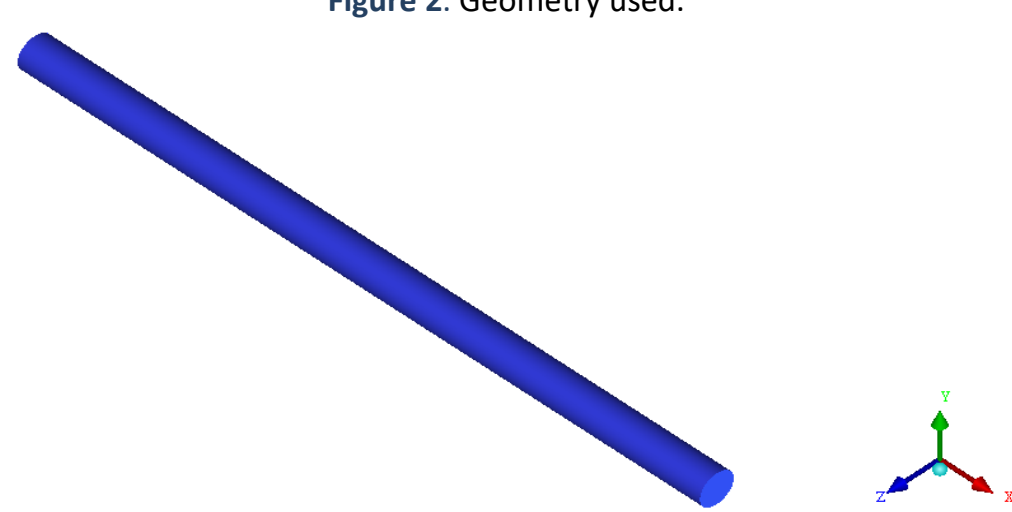

Figure 3. Geometry composed only for a straight section.
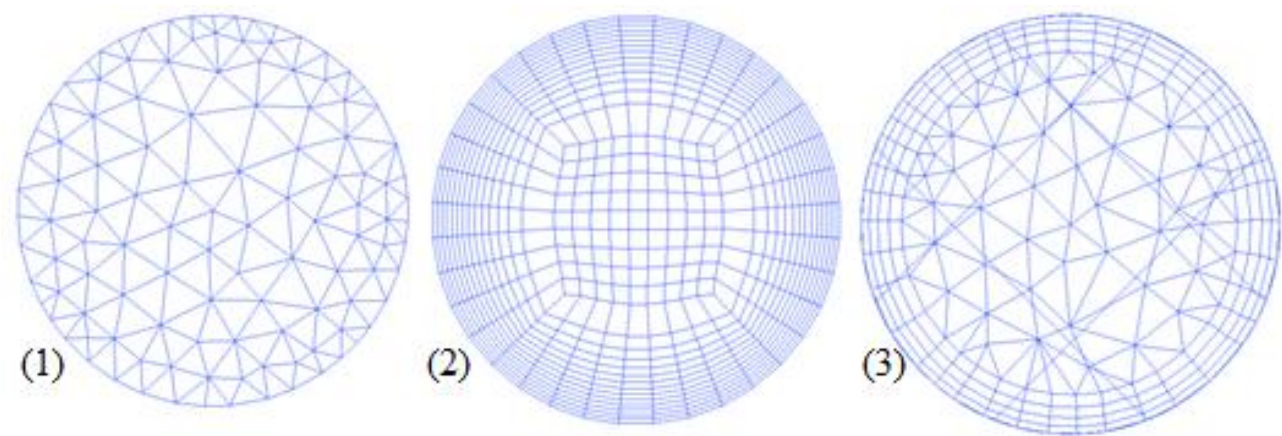

Figure 4. Tetrahedral Unstructured, Hexahedral Structured, and Tetrahedral-Prismatic Unstructured meshes, respectively.

Table 1. Meshes Generated.

\begin{tabular}{|c|c|c|c|}
\hline \multicolumn{4}{|c|}{ Type of Mesh (Type of element) } \\
\hline \multirow{5}{*}{ 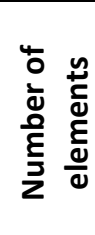 } & Structured (Hex) & Unstructured (Tetra) & Unstructured (Tetra/Prism) \\
\hline & 306,153 & 307,712 & 306,859 \\
\hline & 576,323 & 576,323 & 568,382 \\
\hline & $1,418,445$ & $1,429,891$ & $1,424,330$ \\
\hline & Straight section: 377,080 & 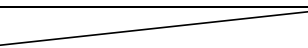 & \\
\hline
\end{tabular}




\subsection{Mathematical modeling}

For the resolution of the proposed problems, a mathematical model based on mass conservation and moment principles was used, considering the following assumptions:

- Isothermal and incompressible flow;

- Steady state;

- Gravitational effects;

- Three-dimensional domain;

- Properties of fluids constant;

- No chemical reactions.

This model adopted a particle model using a Eulerian-Eulerian formulation, in which the gas is considered the dispersed phase. Such formulation, known as multifluid approach, is an extension of the single-phase mathematical modeling for multiphase flow. It is typical of this type of formulation that interactions between the phases are expressed continuously, requiring the correct determination of the volume control. Properties such as temperature and velocity are representative to the set. The equations governing the problem are represented below (Marinho, 2012):

$\nabla \cdot\left(r_{\alpha} \rho_{\alpha} \vec{U}_{\alpha}\right)=0$

$\nabla \cdot\left[\mathrm{r}_{\alpha}\left(\rho_{\alpha} \overrightarrow{\mathrm{U}}_{\alpha} \otimes \overrightarrow{\mathrm{U}}_{\alpha}\right)\right]=-\mathrm{r}_{\alpha} \nabla_{\mathrm{p}}+$

$+\nabla \cdot\left[\mathrm{r}_{\alpha}\left(\tau_{\alpha}+\tau_{\alpha}^{\mathrm{turb}}\right)\right]+\overrightarrow{\mathrm{S}}_{\mathrm{MS} \alpha}+\overrightarrow{\mathrm{M}}_{\alpha}$

Equations 1 and 2 represent, respectively, the conservation of mass and momentum in fluid domain. Where $U_{\alpha}, r_{\alpha}$ and $\rho_{\alpha}$ are, respectively, the real 3D velocity, volumetric fraction and density of a given phase. The term $\vec{S}_{\mathrm{MS} \alpha}$ in Equation 2 represents the movement of forces due to external interactions and $\tau_{\propto}^{\text {turb }}$ refers to Reynolds stresses in the $\alpha$ phase. The term $\vec{M}_{\alpha}$ represents the interfacial forces acting on the $\alpha$ phase due to the presence of other forces. This parameter can be calculated using Equation 3 (Marinho, 2012):

$\overrightarrow{\mathrm{M}}_{\alpha}=\mathrm{C}_{\mathrm{D}} \rho_{\alpha \beta} \mathrm{A}_{\alpha \beta}\left|\overrightarrow{\mathrm{U}}_{\beta}-\overrightarrow{\mathrm{U}}_{\alpha}\right|\left(\overrightarrow{\mathrm{U}}_{\beta}-\overrightarrow{\mathrm{U}}_{\alpha}\right)$

$C_{D}$ is the drag coefficient and $A_{\alpha \beta}$ is the interfacial area of density, which, for the particle model, can be calculated according to the volume fraction $r_{b}$ and the average particle diameter $d_{B}$, according Equation 4 (Marinho, 2008). The interfacial area of density was constant in all simulations, since the average particle diameter and volume fraction were determined.

$A_{\alpha \beta}=\frac{6 r_{\alpha}}{d_{\beta}}$

To validate the results obtained, were used the Lockhart \& Martinelli (1949) and the Kim, Kojasoy, and Guo (2008) correlations.

The Lockhart and Martinelli correlation was used to calculate the pressure drop in the straight section. This correlation allows calculating the pressure drop in gas-liquid two-phase flow, considering it to be isothermal and in steady state, to have a horizontal pipe flow, and to present a thermodynamic equilibrium between the phases in contact. The correlation assumes that the pressure gradient of the two-phase flow is the same as would occur if only one phase was flowing in the pipe under the same conditions of two-phase flow (5), multiplied by an empirical factor according to (6) and (7).

$\frac{\Delta \mathrm{P}}{\Delta \mathrm{L}}=\frac{\rho \mathrm{fv}^{2}}{2 \mathrm{D}}$

$\left(\frac{\Delta \mathrm{P}}{\Delta \mathrm{L}}\right)_{\mathrm{BF}}=\gamma_{\mathrm{L}}\left(\frac{\Delta \mathrm{P}}{\Delta \mathrm{L}}\right)_{\mathrm{L}}$

$\left(\frac{\Delta \mathrm{P}}{\Delta \mathrm{L}}\right)_{\mathrm{BF}}=\mathrm{v}_{\mathrm{G}}\left(\frac{\Delta \mathrm{P}}{\Delta \mathrm{L}}\right)_{\mathrm{G}}$

Here, $\frac{\Delta \mathrm{P}}{\Delta \mathrm{L}}$ is the single-phase pressure drop of any fluid, $\left(\frac{\Delta \mathrm{P}}{\Delta \mathrm{L}}\right)_{\mathrm{L}}$ and $\left(\frac{\Delta \mathrm{P}}{\Delta \mathrm{L}}\right)_{\mathrm{G}}$ are, respectively, the singlephase pressure drop of liquid and gas and $\left(\frac{\Delta \mathrm{P}}{\Delta \mathrm{L}}\right)_{\mathrm{BF}}$ is the two-phase pressure drop. $\gamma_{\mathrm{L}}$ and $\gamma_{\mathrm{G}}$ are empirical factors.

To calculate the pressure drop in the connection, a correlation adapted by Kim, Kojasoy, and Guo was used for $45^{\circ}$ and $90^{\circ}$ connections for two-phase flow (8).

$\left(\frac{\mathrm{dp}}{\mathrm{dz}}\right)_{\mathrm{F}}^{2 \emptyset}=\emptyset_{\mathrm{F}}^{2}\left(\frac{\mathrm{dp}}{\mathrm{dz}}\right)_{\mathrm{Ff}}^{\mathrm{f}}$

Where $\left(\frac{\mathrm{dp}}{\mathrm{dz}}\right)_{\mathrm{F}}^{2 \emptyset}$ is the two-phase pressure drop in the connection, $\varnothing_{F}^{2}$ is a correction factor to the curve, and $\left(\frac{\mathrm{dp}}{\mathrm{dz}}\right)_{\mathrm{Ff}}^{\mathrm{f}}$ is the two-phase pressure drop. In the 
proposed problem were considered rough effects and the acceleration of gravity. The Darcy friction factor was calculated by the following equation:

$\mathrm{f}=$

$=\left\{-2\left[\log \left(\left(\frac{\varepsilon}{3.7 \mathrm{DI}}\right)\right.\right.\right.$

$\left.\left.\left.+\left(\frac{\left(1.66 \ln \left(\mathrm{N}_{\mathrm{Re}}\right)-1.07\right)}{\mathrm{N}_{\mathrm{Re}}}\right)\right)\right]\right\}^{-2}$

Where $\mathrm{N}_{\mathrm{Re}}$ is the Reynolds number, $f$ is the friction factor, $\varepsilon$ is the absolute roughness $(\mathrm{m})$, and $\mathrm{DI}$ is the internal diameter of the pipe $(\mathrm{m})$.

\subsection{Boundary conditions and physical properties of fluids}

Tables 2 and 3 show the physical properties of the fluids used and the boundary conditions applied to the numerical mesh.

The homogeneous model was considered in the simulations. The convergence criteria adopted were a maximum 200 interactions or a RMS equal to $10^{-6}$.

\subsection{Analyzed cases}

The following case studies were developed:

I - Simulation of a structured hexahedral mesh composed only of a straight section in order to estimate the entry velocity in the curved section;

II - Simulation of the hexahedral structured meshes (306,153; 576,408; and 1,453,364 elements), tetrahedral unstructured meshes (307,712; 576,408; and 1,429,891 elements) and tetrahedral-prismatic unstructured meshes (306,859; 568,382; and 1,429,891 elements), all with a $90^{\circ}$ connection.

\section{RESULTS AND DISCUSSIONS}

The results obtained from Case I can be observed in Table 4.

The modeling adopted for Case I suited the problem, since the pressure drop obtained with the simulation showed a deviation of $0.15 \%$ when compared to the Lockhart and Martinelli correlation. Therefore, the output velocity for the straight sector was estimated.

Table 2. Physical properties of used fluids.

\begin{tabular}{lll}
\hline Fluid & Density $\left(\mathrm{kg} / \mathrm{m}^{\mathbf{3}}\right)$ & Dynamic Viscosity (Pa.s) \\
\hline Oil $^{(\mathrm{a})}$ & 868.7 & 0.1 \\
Gas $^{(\mathrm{b})}$ & 0.78 & $1.0816 \times 10^{-6}$ \\
\hline
\end{tabular}

Source: (a) Cunha, 2010; (b) COPERGÁs, 2015.

Table 3. Boundary conditions.

\begin{tabular}{lc}
\hline Tube inlet section & $v=7.5 \mathrm{~m} / \mathrm{s}$ \\
Tube outlet section & $\mathrm{p}=101,325 \mathrm{~Pa}$ \\
Roughness of the tube wall & $\varepsilon=4.56 \cdot 10^{-6} \mathrm{~m}$ \\
Volume fraction of fluids & $r_{\mathrm{o}}=0.9 ; \mathrm{r}_{\mathrm{g}}=0.1$
\end{tabular}

Table 4. Results of Case I.

\begin{tabular}{rcccc}
\hline Number of elements & Numerical $\Delta \mathbf{P}(\mathrm{Pa})$ & Analytical $\Delta \mathbf{P}(\mathbf{P a})$ & Deviation $(\%)$ & Output velocity $(\mathrm{m} / \mathrm{s})$ \\
\hline 377,080 & 35,508 & $35,541.92$ & $0.15 \%$ & 4.4
\end{tabular}


Table 5. Results of simulations related to hexahedral structured meshes.

\begin{tabular}{cccc}
\hline Number of elements & Numerical $\Delta \mathbf{P}(\mathbf{P a})$ & Analytical $\Delta \mathbf{P}(\mathbf{P a})$ & Deviation (\%) \\
\hline 306,153 & $55,005.6$ & $51,217.1$ & $7.39 \%$ \\
576,408 & 54,727 & $51,217.1$ & $6.85 \%$ \\
$1,453,364$ & $54,462.7$ & $51,217.1$ & $6.33 \%$ \\
\hline
\end{tabular}

Table 6. Quality of hexahedral-structured meshes.

\begin{tabular}{cccc} 
& & Meshes & \\
\hline Quality & $\mathbf{3 0 6 , 1 5 3}$ & $\mathbf{5 7 6 , 4 0 8}$ & $\mathbf{1 , 4 5 3 , 3 6 4}$ \\
\hline $0-0.3$ & $0 \%$ & $0 \%$ & $0 \%$ \\
$0.3-0.4$ & $0 \%$ & $0 \%$ & $0 \%$ \\
$0.4-0.5$ & $0 \%$ & $0 \%$ & $0 \%$ \\
$0.5-0.6$ & $1.249 \%$ & $0.017 \%$ & $0 \%$ \\
$0.6-0.7$ & $1.319 \%$ & $1.148 \%$ & $0.179 \%$ \\
$0.7-0.8$ & $4.659 \%$ & $3.56 \%$ & $1.447 \%$ \\
$0.8-0.9$ & $22.66 \%$ & $9.38 \%$ & $2.953 \%$ \\
$0.9-1$ & $70.113 \%$ & $85.896 \%$ & $95.42 \%$
\end{tabular}

The Kim, Kojasoy, and Guo (2008) correlation was used with the output velocity obtained in Case I to find the analytical pressure drop to the $90^{\circ}$ junction in Case II. Adding to the pressure drop of the straight sector (equal to $35,541.92 \mathrm{~Pa}$ ) to that obtained in the junction (equal to $15,675.18 \mathrm{~Pa}$ ) was found the analytical total pressure drop observed in the pipe for Case II, equal to 51,217.1 Pa.

Simulation results the corresponding analytical result of the pressure drop, respective errors, and the meshes qualities used in the Case II are shown in Tables 5 to 10.

The ICEM CFD", using the "Mesh Display Quality" function, determines the overall quality of the mesh on a scale ranging from 0 (zero) to 1 (one). It is recommended that the quality of the meshes are higher than 0.3 (Ansys, 2011).

One can observe from Tables 5 and 6 that, increasing number of elements, there is an improvement in the quality of results and structured hexahedral meshes. This quality increase is a consequence of a better adaptation to the proposed geometry enabled by the increase in number of elements. Consequently, there is a decrease of $14.34 \%$ in the deviation of the numerical pressure drop comparing the results of the meshes with higher and lower number of elements. Other authors also used mesh tests and observed that the number of elements has an influence on the results (Alves, 2012; Araújo et al., 2015; Coelho, 2011; Freitas, 2009; Souza, 2011).

The difference between the results obtained from hexahedral structured meshes with different number of elements can be seen in Figure 5, where the pressure distribution is located in the radial region immediately after the curve to the meshes with 304,153 elements (1) and 1,453,364 elements (2).

Due to the smaller size of the elements, and consequently the greater number of layers present in (2), the pressure presents a better distribution even in the region near the pipe center. This increased discretization provided more accurate calculations with minor deviations in the results, as noted in Table 5. 

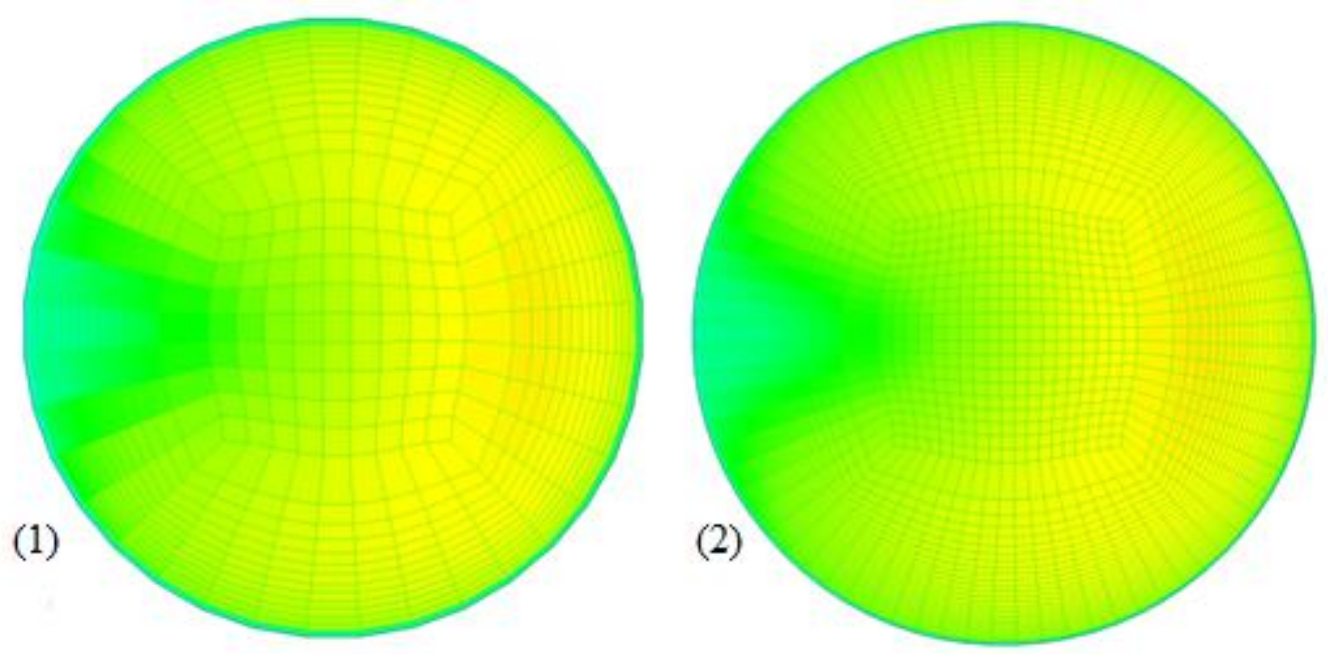

Figure 5. Pressure distribution of the radial region immediately after the curve to the mesh of 304,153 and $1,453,364$ elements.

Through the Tables 7 and 8, observing tetrahedral unstructured meshes, the number of elements increase in the mesh also increasing the quality of it, having a similar behavior to that seen for hexahedral structured meshes.

There was an increase in mesh quality with the increase in number of elements forming tetrahedral unstructured meshes (Table 8). This increase led to a reduction of differences between numerical and analytical results in the order of $47 \%$.

The same behavior was observed for tetrahedral-prismatic meshes (Tables 9 and 10). For this type of mesh, the increase in the number

Table 7. Results of simulations related to tetrahedral unstructured meshes.

\begin{tabular}{cccc}
\hline Number of elements & Numerical $\Delta \mathbf{P}(\mathbf{P a})$ & Analytical $\Delta \mathbf{P}(\mathrm{Pa})$ & Deviation $(\%)$ \\
\hline 307,712 & $52,060.2$ & $51,217.1$ & $1.62 \%$ \\
576,408 & 54,727 & $51,217.1$ & $1.11 \%$ \\
$1,429,891$ & $51,659.7$ & $51,217.1$ & $0.85 \%$ \\
\hline
\end{tabular}

Table 8. Quality of tetrahedral unstructured meshes.

\begin{tabular}{cccc} 
& \multicolumn{3}{c}{ Meshes } \\
\hline Quality & $\mathbf{3 0 7 , 7 1 2}$ & $\mathbf{5 7 6 , 4 0 8}$ & $\mathbf{1 , 4 2 9 , 8 9 1}$ \\
\hline $0-0.3$ & $0 \%$ & $0 \%$ & $0 \%$ \\
$0.3-0.4$ & $0.001 \%$ & $0.002 \%$ & $0.007 \%$ \\
$0.4-0.5$ & $11.69 \%$ & $12.527 \%$ & $10.506 \%$ \\
$0.5-0.6$ & $12.423 \%$ & $12.439 \%$ & $10.523 \%$ \\
$0.6-0.7$ & $14.33 \%$ & $13.445 \%$ & $11.498 \%$ \\
$0.7-0.8$ & $16.6 \%$ & $15.348 \%$ & $12.987 \%$ \\
$0.8-0.9$ & $26.494 \%$ & $21.9 \%$ & $20.156 \%$ \\
$0.9-1$ & $18.462 \%$ & $24.339 \%$ & $34.323 \%$ \\
\hline
\end{tabular}


Table 9. Results of simulations related to tetrahedral-prismatic unstructured meshes.

\begin{tabular}{cccc}
\hline Number of elements & Numerical $\Delta \mathbf{P}(\mathbf{P a})$ & Analytical $\Delta \mathbf{P}(\mathbf{P a})$ & Deviation $(\%)$ \\
\hline 306,859 & $54,958.7$ & $51,217.1$ & $7.30 \%$ \\
568,382 & $54,605.0$ & $51,217.1$ & $6.61 \%$ \\
$1,429,891$ & $53,726.0$ & $51,217.1$ & $4.89 \%$ \\
\hline
\end{tabular}

Table 10. Quality of tetrahedral-prismatic unstructured meshes.

\begin{tabular}{cccc} 
& & \multicolumn{2}{c}{ Meshes } \\
\cline { 3 - 4 } Quality & $\mathbf{3 0 6 , 8 5 9}$ & $\mathbf{5 6 8 , 3 8 2}$ & $\mathbf{1 , 4 2 9 , 8 9 1}$ \\
\hline $0-0.3$ & $1.130 \%$ & $0.365 \%$ & $0.171 \%$ \\
$0.3-0.4$ & $6.710 \%$ & $5.894 \%$ & $5.084 \%$ \\
$0.4-0.5$ & $8.503 \%$ & $8.212 \%$ & $7.437 \%$ \\
$0.5-0.6$ & $7.965 \%$ & $7.645 \%$ & $7.322 \%$ \\
$0.6-0.7$ & $7.362 \%$ & $7.185 \%$ & $6.966 \%$ \\
$0.7-0.8$ & $8.364 \%$ & $8.998 \%$ & $8.784 \%$ \\
$0.8-0.9$ & $14.375 \%$ & $9.724 \%$ & $9.788 \%$ \\
$0.9-1$ & $45.591 \%$ & $51.977 \%$ & $54.448 \%$ \\
\hline
\end{tabular}

of elements has provided a reduction of deviations of approximately $33 \%$.

Although the meshes are similar in element organization, one could observe that only those with tetrahedral elements provided significantly lower deviations to those obtained with the results of the meshes that had prismatic elements. The prismatic elements are best suited to capture the physical effects of the boundary layers (Ansys, 2011). Therefore, it is possible that the prism layer is not appropriate to the geometry used, mainly in the curved region.

Another factor that should have influenced the difference between results of unstructured meshes is the quality of the tetrahedral-prismatic mesh. In Table 10 one can observe that a small part of the elements of the meshes containing prismatic elements had quality between zero and 0.3 , below the recommended.

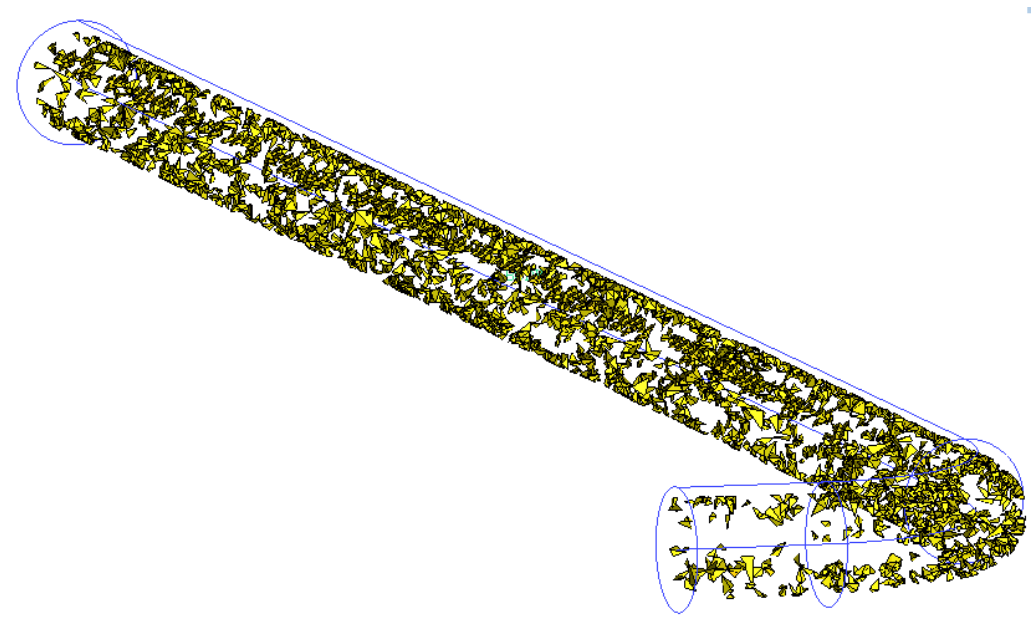

Figure 6. Location of elements with quality less than 0.3 in mesh with 1,429,891 elements. 
A search for elements having quality lower than 0.3 for the tetrahedral-prismatic mesh with $1,429,891$ elements shows, as can be seen in Figure 6 , that these elements were in the transition zone between the prismatic layer in the pipe wall and the tetrahedral elements located closer to the center.

One could also verify that the lower the number of elements of the tetrahedral-prismatic mesh was, the more elements of quality below 0.3 it possessed. Table 10 shows the percentage of elements with low quality, that is, $1.130 \%$ in the smaller mesh $(306,859$ elements) and $0,171 \%$ in the largest mesh $(1,429,891$ elements). This is due to the fact that in the smaller mesh elements are larger and, therefore, have greater difficulty to adapt in the transition to prismatic layer

\section{CONCLUSIONS}

From the results obtained, it is possible to notice that the numerical mesh exerts a significant influence on the results. This influence was observed from the variation of the number of elements of the meshes and the different types of elements that compose them.

In all cases, it was observed that, with an addition in the number of elements in the mesh, the numerical value of the pressure drop approached the ones that were obtained analytically. Decreases of $1.06 \%, 0.77 \%$, and $2.41 \%$ were observed in the deviation of hexahedral structured, tetrahedral unstructured, and tetrahedral-prismatic meshes results, respectively.

Among the types of meshes used in the analysis of Case II, the one that best suited the proposed problem was the unstructured tetrahedral mesh, with deviations between $1.62 \%$ and $0.85 \%$. The least suited mesh was the hexahedral structured, with deviations between $7.39 \%$ and $6.33 \%$. However, the same type of mesh was satisfactorily adapted to the analysis of a straight pipe, with a deviation of $0.15 \%$. The disparity between the deviations of the two cases for the same type of mesh shows that the geometry of the problem must be taken into account when choosing the numerical mesh to be used.

It is worth emphasizing that, despite the presence of prismatic elements in tetrahedralprismatic unstructured meshes, these types provided deviations up to $7.30 \%$. The noneffectiveness of prism layers may also have some kind of consequence in geometry. There is a possibility that the presence of prismatic layers did not cause the expected effect due to an inadequacy for the region of $90^{\circ}$ curve and a loss of mesh quality in the moment of its insertion in the transition zone between the prisms and tetrahedral elements.

Despite the observations, one can conclude that the appropriate choice of the numerical mesh to be used is essential in obtaining results with greater reliability. It is crucial that the results obtained in CFD analyses provide accurate results, especially in the case of problems with large-scale applications and with enormous economic importance, such as this one. The accuracy of the results depends on the factors analyzed in this work, such as influence of number of elements, type of mesh and behavior in relation to the geometry used.

\section{NOMENCLATURE}

\section{Latin letters:}

$A_{\alpha \beta} \quad$ Density of interfacial area $\quad \mathrm{m}^{-1}$

$C_{D} \quad$ Drag coefficient

$D \quad$ Pipe diameter m

$d_{6} \quad$ Particle diameter m

$f \quad$ Friction factor -

$L \quad$ Pipe length $m$

$M_{\alpha} \quad$ Interfacial forces $\quad \mathrm{N} / \mathrm{m}^{3}$

$p \quad$ Pressure $\quad \mathrm{Pa}$

$r_{\alpha} \quad$ Volume fraction of $\alpha$ -

$R \quad$ phase

$R \quad$ Pipe radius m

$S_{M S \alpha} \quad$ Momentum forces $\quad \mathrm{N} / \mathrm{m}^{3}$

$v \quad$ Speed $\mathrm{m} / \mathrm{s}$

$U_{O} \quad$ Velocity of oil in center $\mathrm{m} / \mathrm{s}$

$\vec{U} \quad$ Velocity vector $\mathrm{m} / \mathrm{s}$

$\varepsilon$ Roughness m

$\triangle P \quad$ Pressure drop $\quad \mathrm{Pa}$ 


\section{Greek letters:}

$\begin{array}{llr}\alpha, b & \text { Phases involved } & - \\ \mu & \text { Dynamic viscosity } & \mathrm{N} . \mathrm{s} / \mathrm{m}^{2} \\ \rho & \text { Density } & \mathrm{kg} / \mathrm{m}^{3} \\ \rho_{\alpha} & \alpha \text { phase density } & \mathrm{kg} / \mathrm{m}^{3} \\ \rho_{\alpha \beta} & \text { Mixture density } & \mathrm{kg} / \mathrm{m}^{3} \\ \tau_{\alpha}^{\text {turb }} & \text { Turbulent Reynolds } & \mathrm{kg} /\left(\mathrm{m} . \mathrm{s}^{2}\right) \\ & \text { stresses for } \alpha \text { phase } & \end{array}$

\section{REFERENCES}

Alves, V. B. Hidrociclone para a Separação do Óleo Residual de Água em Refinarias, Dissertação de Mestrado, Universidade Federal do Rio de Janeiro, Rio de Janeiro/RJ. 2012. (in Portuguese)

ANSYS CFX 13. User manual. Ansys Europe Ltd., 2011.

Araujo, C. A. O.; Scheid, C. M.; Klein, T. S.; Loureiro, J. B. R.; Medrono, R. A. Eficiência de Separação de Hidrociclones para a Separação de Mistura Óleo-Água com Alto Teor de Óleo: Comparação Entre Resultados Simulados e Experimentais. Congresso Brasileiro de Sistemas Particulados, 37 ed., São Carlos/SP. 2015. (in Portuguese)

Carvalho, S. C. Modelo de Mistura Aplicado para a Previsão de Holdup e Gradiente de Pressão Bifásico em Duto Anular de Grade Diâmetro. Dissertação de mestrado, Universidade de São Paulo, São Carlos/SP. 2013. (in Portuguese)

Coelho, D. B. Desempenho de um Hidrociclone para separação de águas oleosas. Monografia, Universidade Federal do Rio Grande do Norte, Natal/RN. 2011.(in Portuguese)

COPERGÁS. Produtos. 2015. Disponível em: <http://www.copergas.com.br/produtos/\#.VbJIJPIV iko>. Accessed on: 24 july 2015. (in Portuguese).

Cunha, A. L. Recuperação Avançada NãoIsotérmica de Óleos Pesados em Reservatórios de Petróleo Via Simulação Numérica. Dissertação de Mestrado, Universidade Federal de Campina Grande, Campina Grande /PB. 2010. (in Portuguese)
Ferreira, D. N.; Marinho, J. L.G. Análise da perda de carga em uma tubulação com vazamento para uma mistura bifásica utilizando uma junção de $90^{\circ}$. Congresso Brasileiro de P\&D em Petróleo e Gás, 8 ed., Curitiba/PR, 2015. (in Portuguese)

Freitas, A. G. B. Modelagem e simulação do tratamento de água oleosa usando hidrociclones, Dissertação, Universidade Federal de Sergipe, São Cristovão/SE. 2009. (in Portuguese)

Gonçalves, N. D. F. Método dos Volumes Finitos em Malhas Não-Estruturadas. Dissertação de Mestrado, Universidade do Porto, Porto. 2007. (in Portuguese)

Kim, S.; Kojasoy, G.; Guo, T. Two-phase minor loss in horizontal bubbly flow with elbows: $45^{\circ}$ and 90 elbows. Chemical Engineering Journal. Pennsylvania, p. 1-6. 21 ago. 2008.

Lockhart, R. W.; Martinelli, R. C. Proposed Correlation of Data for Isotermal Two-Phase, Two Component Flow in Pipes, Chermical Engineering Progress, Vol. 45, 1949.

Maliska, C. R. Transferência de Calor e Mecânica dos Fluidos Computacional. Rio de Janeiro: LTC. 2004. (in Portuguese)

Marinho, J. L. G. Escoamento anular isotérmico de óleos pesados e água em bifurcações angulares: modelagem e simulação. Tese de doutorado, Universidade Federal de Campina Grande, 2012. (in Portuguese)

Marinho, J. L. G. Estudo do Escoamento Multifásico Tipo Bolha de Taylor em Dutos em Conexões Curvadas. Dissertação de Mestrado, Universidade Federal de Campina Grande, Campina Grande/PB, 2008. (in Portuguese)

Oliveira, L. M. T. M.; Marinho, J. L. G.; Pimentel, W. R. O.; Carvalho, S. H. V. Modeling and Simulation of Secondary Recovery Applied to an Offshore Ultra-Deep Environment. Brazilian Journal of Petroleum and Gas, v. 10, n. 1, p. 033047. 2016.

Salim, A.; Fourar, M.; Pironon, J.; Sausse, J. OilWater Two-Phase Flow in Microchannels: Flow Patterns and Pressure Drop Measurements. The Canadian Journal of Chermical Engineering, v. 86, p. 978-988. 2008.

https://doi.org/10.1002/cjce.20108 
Santos, J. S. S.; Farias Neto, S. R.; Lima, A. G. B.; Crivelaro, K. C. O. Transporte de Óleos Pesados em Catenárias Via Técnica Core-Flow - Modelagem e Simulação. VI Congresso Nacional de Engenharia Mecânica. Campina Grande/PB, 2010. (in Portuguese)

Silva, J. Q. Análise Numérica da Perda de Carga em Escoamentos de Fluidos não Newtonianos na Região de Entrada de Tubos. Monografia, Universidade Federal do Espírito Santo, Vitória. 2008. (in Portuguese)

Silva, L. D. S.; Marinho, J. L. G. Numerical Study of the Influence of Gas Volume Fraction on the Two-phase Flow of Heavy Oil and Natural Gas Mixtures in an Oil Well. Brazilian Journal of Petroleum and Gas, v. 8, n. 2, p. 49-55, 2014. https://doi.org/10.5419/bipg2014-0004

Silva, L. D. S.; Marinho, J. L. G. Study on Pressure Drop and Liquid Volume Fraction of the Oil-Gas Flow in a Vertical Pipe Using CFX and the Beggs and Brill Correlation: Viscosity Effects. Brazilian Journal of Petroleum and Gas, v. 10, n. 1, p. 01-08. 2016.

Silva, V. G. S.; Soletti, J. I.; Marinho, J. L. G.; Carvalho, S. H. V. Simulação em CFD de um Tanque de Mistura Utilizando Diferentes Tipos de Malha. Ibero-Latin American Congress on Computational Methods in Engineering, 36 ed., Rio de Janeiro/RJ. 2015. (in Portuguese) https://doi.org/10.20906/cps/cilamce2015-0533
Souza, L.G. V. M. Estudo do Refino de Malha em um Modelo Computacional de Bomba de Cavidades Progressivas. Monografia, Universidade Federal do Rio Grande do Norte, Natal/RN. 2011.(in Portuguese)

Souza, R.G. S. Escoamento Bifásico Líquido-Gás: Previsão de Gradientes de Pressão com a Correlação de Lockhart \& Martinelli e Fluidodinâmica Computacional. Monografia, Universidade Federal do Rio de Janeiro, Rio de Janeiro/RJ, 2009. (in Portuguese)

Teleken, J. G.; Werle, L. O.; laçanã, G. B. P.; Marangoni, C.; Meneguelo, A. P.; Ricardo, A. F. M. Fluid-Dynamics Study of Multiphase Flow in a Sieve Tray of a Distillation Column. $20^{\circ}$ European Symposium on Computer Aided Process Engineering, Ischia, Naples. 2010. https://doi.org/10.1016/S1570-7946(10)28013-6 